\title{
Comunicação sensorial no Museu Câmara Cascudo da Universidade Federal do Rio Grande do Norte: uma experiência didática Sensory communication at the Universidade Federal do Rio Grande do Norte's Museu Câmara Cascudo: a didactic experience
}

\author{
Elizabeth Romani, Helena Rugai Bastos \& Isadora Rocha de Medeiros Liberalino
}

design universal, comunicação sensorial, acessibilidade, museu

O artigo apresenta experiência de projeto desenvolvida em componente curricular do Bacharelado em Design na Universidade Federal do Rio Grande do Norte [UFRN], envolvendo trocas entre docentes de diferentes áreas do conhecimento, discentes e consultores cegos. Objetivou-se na disciplina "Design inclusivo e artefatos gráficos", a sensibilização dos discentes para questões sobre política de inclusão e de acessibilidade em espaços culturais, a fim de incorporar novas perspectivas na produção de materiais inclusivos para pessoas com deficiência, sobretudo para cegos e pessoas com baixa visão. No segundo semestre de 2018, foram ministrados conceitos, fundamentos e conteúdo, promovendo a discussão sobre design inclusivo, artefatos gráficos e acessibilidade cultural, comunicação e divulgação de conhecimento em espaços culturais, e metodologias participativas aplicadas ao design. A reflexão sobre tal conteúdo conduziu o desenvolvimento de projeto de artefatos para a exposição "Aves e evolução: uma perspectiva histórica" instalada no Museu Câmara Cascudo, selecionado por sua relevância no Rio Grande do Norte como difusor do patrimônio histórico, artístico, cultural e científico. Articulando ensino na graduação, extensão e pesquisa, no primeiro semestre de 2019 , foram propostas ações de pesquisa e extensão no Museu, o que permitiu aperfeiçoar os artefatos desenvolvidos pelos discentes para implantá-los no espaço expositivo. A discussão sobre resultados obtidos pretende contribuir para debates sobre design inclusivo e apontar caminhos para a produção da comunicação sensorial, utilizando para isso recursos e tecnologia de baixo custo. A experiência deve conduzir projetos de extensão e pesquisa, objetivando aperfeiçoar investigações e desenvolvimento de recursos sensoriais em museus universitários locais.

\section{universal design, sensory communication, accessibility, museum}

The article presents an experience from a project carried out within a curricular component of the Bachelor's in Design undergraduate program at the Universidade Federal do Rio Grande do Norte [UFRN], involving exchanges among professors from different areas of knowledge, students and blind consultants. In the subject called Design inclusivo e artefatos gráficos, it was aimed to sensitize students to matters regarding inclusion and accessibility policies in cultural spaces in order to incorporate new perspectives in the production of inclusive materials for people with disabilities, especially for the blind and visually impaired. In the second semester of 2018, concepts, fundaments and content were taught, promoting the discussion about inclusive design, graphic artifacts and cultural accessibility, communication and knowledge dissemination in cultural spaces and collaborative methodologies applied to design. Reflection about such content conducted the project development of artifacts for the exposition Aves e evolução: uma perspectiva histórica, installed at the Museu Câmara Cascudo, chosen due to its relevance in the state of Rio Grande do Norte as a promoter of the historic, artistic, cultural and scientific heritage. Articulating teaching, extension and research, in the first semester of 2019, research and extension activities were proposed at the museum, which made it possible to improve the artifacts developed by the students to be installed at the exposition area. Discussion about the results obtained intends to contribute to debates about inclusive design and lead to the production of sensory communication through low-cost technology and resources. The experience must carry out extension and research projects, aiming to improve studies and development of sensory resources in local university museums.

Anais do 9 CIDI e 9 CONGIC

Luciane Maria Fadel, Carla Spinillo, Anderson Horta, Cristina Portugal (orgs.)

Sociedade Brasileira de Design da Informação - SBDI

Belo Horizonte | Brasil | 2019

ISBN 978-85-212-1728-2
Proceedings of the 9th CIDI and 9th CONGIC

Luciane Maria Fadel, Carla Spinillo, Anderson Horta, Cristina Portugal (orgs.)

Sociedade Brasileira de Design da Informação - SBDI Belo Horizonte | Brazil | 2019

ISBN 978-85-212-1728-2 


\section{Introdução}

Este artigo propõe apresentar experiência didática desenvolvida em disciplina do Bacharelado em Design da Universidade Federal do Rio Grande do Norte [UFRN] intitulada "Design inclusivo e artefatos gráficos", ministrada pela professora Elizabeth Romani no segundo semestre de 2018. O componente curricular tem como objetivo sensibilizar futuros designers para questões sobre política de inclusão e de acessibilidade em espaços de cultura, a fim de incorporar novas perspectivas na produção de materiais inclusivos para pessoas com deficiência, sobretudo para cegos e pessoas com baixa visão. Foram ministrados conceitos, fundamentos e conteúdo para posterior desenvolvimento de projeto, levando em conta abordagens metodológicas participativas, princípios do codesign (Lupton, 2013) e a interrelação entre docentes de diferentes áreas do conhecimento, discentes e consultores cegos. A reflexão e o exame sobre tal conteúdo promoveram o desenvolvimento de artefatos gráficos para a exposição "Aves e evolução: uma perspectiva histórica" instalada no Museu Câmara Cascudo [MCC] da UFRN, selecionado por sua relevância no Rio Grande do Norte [RN] como difusor do patrimônio histórico, artístico, cultural e científico.

O artigo contextualiza a experiência realizada, aduzindo questões relacionadas ao MCC, à política de inclusão e barreiras comunicacionais e educacionais em espaços culturais. Adiante, é apresentado o processo de desenvolvimento da disciplina, incluindo procedimentos didáticos e a condução das atividades, que resultaram na concepção de artefatos para a exposição. Para ilustrar são apresentados três projetos e, por fim, o artigo propõe discutir os resultados obtidos.

\section{Acessibilidade cultural e o Museu Câmara Cascudo}

O MCC é responsável pela salvaguarda de acervo arqueológico significativo. Apesar de ser reconhecido como difusor do patrimônio histórico, artístico, cultural, científico e como propagador sociocultural na região, não apresenta uma política institucional de inclusão. É um desafio para os museus brasileiros o financiamento de iniciativas que promovam acessibilidade, o que inclui ações educativas inclusivas. Os projetos de acessibilidade em espaços culturais brasileiros é um processo ainda em construção. Corrobora a afirmação os dados divulgados pelo Instituto Brasileiro de Museus (2019): apenas 19,63\% das instituições cadastradas possuem algum tipo de acessibilidade. Para além dos obstáculos financeiros, os museus enfrentam carência de profissionais especializados em projetos de acessibilidade cultural. Entretanto, é necessário atender diversos públicos com diferentes necessidades, buscando novos modelos curatoriais e expográficos. Não se trata de uma novidade: a Declaração de Carracas de 1992 propôs discutir a missão dos museus como agentes do desenvolvimento integral da América Latina. $O$ documento atesta a relevância da comunicação como elemento-chave para o desenvolvimento de estratégias de acessibilidade (Araujo; Bruno, 1995). A partir da revisão do papel dos museus, foi indispensável questionar modelos tradicionais de museologia e transformar a orientação do planejamento estratégico nos museus (Sarraf, 2015). Assim, foram implantadas estratégias diferenciadas para a atração e fidelização dos visitantes, considerando a acessibilidade física e sensorial, as novas formas de apresentar e disponibilizar conteúdos para ampliar a experiência vivenciada nesses espaços. É importante ressaltar, que estes princípios manifestam a necessidade de criar espaços que promovam a convivência, a compreensão de públicos diversos e, com atenção às restrições e às potencialidades de cada indivíduo, a valorização do ser humano e a melhoria de qualidade de vida.

O MCC é uma unidade museológica universitária pública, por isso carece de recursos para implantação e manutenção de ações propostas por servidores, oriundos, em sua maioria, de financiamentos provenientes de editais da UFRN para promoção do ensino, da extensão e da pesquisa. Em 2018, a partir de nova proposta museológica o planejamento e montagem das exposições realizadas no Museu passaram a respeitar, desde o processo de concepção, questões relacionadas à inclusão e à acessibilidade. Os projetos das exposições passaram a ser discutidos e elaborados por comissão técnica composta por membros dos setores do MCC, 
docentes e técnicos de diferentes departamentos e áreas da UFRN. As comissões multidisciplinares devem considerar aspectos técnicos para acessibilidade cultural, englobando acessibilidade física e sensorial (Tojal, 2010). Para além da eliminação de barreiras físicas nos edifícios, dos espaços de circulação, das salas expositivas e a preocupação com iluminação e conforto ambiental, deve-se considerar questões comunicacionais e de acesso à informação, acolhendo o público da entrada até a exposição do conteúdo, o que inclui a comunicação escrita, visual, sonora, audiovisual e as experiências multissensoriais vivenciadas pelos visitantes. Outrossim, o conselho do MCC busca renovar seu planejamento estratégico para afirmar a função sociocultural e respeitar a acessibilidade física e sensorial aos bens culturais. Tal iniciativa atende à Lei Brasileira de Inclusão da Pessoa com Deficiência (2015). Porém, a que se considerar a escassez de profissionais especializados em acessibilidade cultural, em especial no RN. Com o intento de estimular a formação e disseminar o conhecimento, ações de extensão, coordenadas por servidores técnicos e docentes da UFRN e articuladas aos propósitos do MCC, promovem oficinas temáticas sobre acessibilidade em espaços culturais para preparar agentes que atuam com museologia. Ações e atividades articuladas ao ensino da graduação, incentivam a concepção de projetos inclusivos para atender necessidades dos diversos públicos. É a partir desse contexto, que se insere a disciplina "Design inclusivo e artefatos gráficos", oferecida pelo Bacharelado em Design da UFRN. Com a meta de incorporar novas perspectivas para produção de materiais inclusivos, o escopo da disciplina é sensibilizar discentes para questões sobre política de inclusão, mormente em espaços culturais.

\section{A experiência didática: contexto e procedimentos}

A docente responsável pela disciplina "Design inclusivo e artefatos gráficos", para o desenvolvimento de atividades e de projeto, buscou parceria com o departamento responsável pelas ações educativas do MCC. Na oportunidade foi selecionada a exposição "Aves e evolução: uma perspectiva histórica", mostra aberta em novembro de 2017. Vale destacar, que durante o planejamento da mostra a nova política de inclusão do MCC não estava implantada, assim, embora a pauta estivesse em discussão, o projeto da exposição não examinou estratégia de acessibilidade. Ainda em cartaz, a exposição apresenta as teorias da evolução por meio de percurso construído por painéis com textos explicativos e imagens ilustrativas. Algumas aves taxidermizadas estão expostas, no entanto, não é permitido o toque. Privilegiando público específico formado por cegos e pessoas com baixa visão, as responsáveis estabeleceram estratégias de comunicação sensorial para a mostra. É importante mencionar que o Museu e a UFRN não dispunham de verba para produção de artefatos ou dispositivos que atendessem a demanda levantada. Assim, as atividades promovidas na disciplina consideraram esta restrição.

No desenvolvimento da disciplina, levou-se em conta princípios do codesign ${ }^{1}$ (Sanders \& Stappers, 2008; Sanders, 2000; Lupton, 2013). Considerando métodos participativos no processo, desde a exposição teórica dos conteúdos até a avaliação dos protótipos, participaram das atividades promovidas dois consultores com deficiência visual. Colaboraram na fase de exposição de conteúdo, três docentes especialistas em educação para pessoas com deficiência. Os métodos de projeto incluíram técnicas de observação participativa para compreender as experiências do público com deficiência, além do processo de avaliação das propostas desenvolvidas, momento em que os consultores puderam expressar suas percepções no uso dos artefatos produzidos. Considerou-se como premissa de projeto processos de fabricação manual e materiais de baixo custo para o desenvolvimento dos recursos de acessibilidade, respeitando a indisponibilidade de tecnologia de fabricação digital e a recursos destinados às ações educativas no Museu.

O processo foi construído a partir das seguintes etapas:

[1] Exposição de conteúdo: aulas expositivas no formato de palestras ministradas pela professora responsável e convidados especialistas. Com o intuito de apresentar e discutir

\footnotetext{
${ }^{1} \mathrm{O}$ termo codesign é usado em sentido abrangente e envolve a ação criativa de designers (formados ou em formação, por se tratar de experiência em disciplina da graduação) e pessoas não especialistas em design, que de maneira colaborativa, participam no processo de desenvolvimento de projeto.
} 
conceitos e fundamentos relacionados com a temática e design inclusivo, foram ministrados conteúdos sobre: terminologia, legislação, desenho universal, audiodescrição, Língua Brasileira de Sinais, código Braille, tecnologia assistiva, materiais impressos acessíveis e métodos e processo de design. Participaram desta fase uma professora especializada em educação para surdos, uma docente especialista em audiodescrição, uma professora que ensina musicografia braille, dois consultores, um cego e outro com baixa visão. A tabela 1 apresenta a organização dos conteúdos ministrados nos encontros semanais e identifica os palestrantes responsáveis. ${ }^{2}$

Tabela 1: Organização dos encontros (palestra/aula) e do conteúdo abordado

\begin{tabular}{l|l|l}
$\begin{array}{l}\text { Palestra/ } \\
\text { aula } \\
\text { expositiva }\end{array}$ & Conteúdo & Responsável/convidado \\
\hline 1 & $\begin{array}{l}\text { Conceitos sobre acessibilidade e } \\
\text { terminologia }\end{array}$ & Elizabeth Romani \\
\hline 2 & Legislação e desenho universal & Elizabeth Romani \\
\hline 3 & Audiodescrição & Andrea Gurgel de Freitas e Bruno Lima \\
\hline 4 & Libras e conceitos & Flávia Roldan Viana \\
\hline 6 & Braille e materiais impressos & Catarina Shin \\
\hline & Tecnologia assistiva & Thiago Cerejeira \\
\hline & Desenvolvimento de projeto & $\begin{array}{l}\text { Elizabeth Romani com a colaboração } \\
\text { dos consultores }\end{array}$ \\
\hline
\end{tabular}

Nesta etapa a proposta de projeto foi apresentada e alguns parâmetros foram estabelecidos quanto aos processos de fabricação manual, o uso de materiais de baixo custo para o desenvolvimento dos artefatos, princípios do codesign e utilização de métodos participativos no processo de design.

[2] Visita ao Laboratório de Acessibilidade da UFRN: vinculado à Comissão Permanente de Apoio a Estudantes com Necessidades Educacionais Especiais da UFRN. O laboratório oferece serviços e disponibiliza material em formato acessível como: digitalização de textos; produção de materiais em formatos acessíveis; empréstimo de tecnologias assistivas; orientação bibliográfica e normalização de trabalhos; orientação e mobilidade; revisão braille; treinamento e capacitação; repositório de informação acessível da UFRN. Os alunos puderam compreender os serviços prestados, o processo de trabalho no laboratório e o funcionamento de algumas das tecnologias assistivas disponíveis no mercado, conhecimentos fundamentais para a seleção de processos de produção dos artefatos.

[3] Visita técnica ao MCC: para compreender demandas da exposição temporária mencionada e aprofundar conhecimento sobre a temática, o conteúdo, a disposição e organização das informações e do espaço expositivo. A visita foi guiada por um dos curadores, o que possibilitou compreender os objetivos curatoriais, as soluções encontradas pela equipe do Museu. Ademais, participaram os consultores, que contribuíram para o levantamento das dificuldades de acesso às informações para pessoas com necessidades específicas.

[4] Levantamento, análise e diagnóstico: após a visita técnica, os discentes formaram 6 grupos de trabalho. Durante esta fase, cada grupo selecionou tópico específico a ser levantado e analisado, levando em conta a disponibilização e a organização do conteúdo e das informações na exposição.

Algumas observações são importantes para compreender as decisões de projeto. Por se tratar de atividade articulada à disciplina, o prazo para desenvolvimento de projeto foi o período letivo, com apresentação final prevista na $1^{\text {a }}$ semana de dezembro de 2018. Considerando o início do semestre na última semana de julho e os encontros descritos nas etapas [1] e [2], o desenvolvimento das etapas seguintes decorreu em 11 semanas. Assim, não foi possível conceber todos os artefatos necessários para tornar a exposição plenamente acessível. No entanto, foi possível analisar o percurso da mostra e considerar pontos específicos, nos quais intervenções poderiam contribuir para uma maior fruição das informações expostas, ${ }^{2} \mathrm{O}$ desenvolvimento de projeto implicou a discussão sobre métodos e processos a partir da apresentação da proposta
na disciplina, realizada na apresentação da disciplina, em aula sobre abordagens metodológicas e parâmetros de projeto, na orientação de projeto. 
contemplando todos os visitantes. Sob a orientação da responsável pelo setor educativo do MCC, cada grupo selecionou um tópico para propor um artefato. Foi necessário levantamento mais específico e análise mais aprofundada sobre cada tópico. O diagnóstico e as propostas iniciais dos artefatos foram apresentados por cada grupo e os resultados foram discutidos coletivamente. Em linhas gerais, as principais questões diziam respeito à inexistência de recursos para a comunicação sensorial e para o acesso ao conteúdo para cegos sobretudo. Em outras palavras, foi constatado que a experiência do visitante estava restrita a artefatos visuais.

É importante ressaltar, que fez parte da etapa [4] o levantamento sobre recursos, materiais e técnicas disponíveis para o desenvolvimento e a produção dos projetos. Nesse caminho, a carência de recursos materiais e de infraestrutura na Instituição, constituíram parâmetros de projeto. A UFRN não dispõe em muitos de seus departamentos e museus equipamentos de fabricação digital para produção de protótipos mais precisos.

[5] Planejamento e desenvolvimento de projeto: a partir do diagnóstico e das propostas iniciais os grupos planejaram métodos e processos para a geração de ideias. Foram apresentadas as propostas: $[\mathrm{A}]$ mapa tátil da sala expositiva; $[\mathrm{B}]$ pranchas em revelo com representação das aves taxidermizadas]; [C] réplica tátil do fóssil Archaeopteryx lithographica; [D] recurso de mediação para representar alterações genéticas; [E] audiodescrição do painel que apresenta linha do tempo e evolução das aves. Foi prevista a disponibilização de legendas em braille e com texto ampliado, atendendo públicos diversos e de acordo com as diretrizes do design universal.

[6] Produção de modelos preliminares e discussão com consultores: os processos artesanais tornaram os procedimentos mais lentos e restringiram o uso de determinados acabamentos. As etapas [4], [5] e [6] foram realizadas em 6 semanas. Durante esse processo, nas orientações aos grupos, a docente constatou que todos consideraram a acessibilidade comunicacional, sobretudo para o cego e para pessoas com baixa visão. Assim, foram convidados um consultor cego e um consultor com baixa visão para analisar e avaliar a eficiência dos conceitos propostos. Nesse momento, os consultores identificaram questões e limites das propostas e sugeriram alterações na configuração formal, no uso dos materiais, assim como na organização das informações.

[7] Produção de modelos finais: o aperfeiçoamento dos projetos e a produção do modelo final foram realizadas em 15 dias.

[8] Avaliação dos consultores para a produção dos artefatos: os modelos finais foram avaliados pelo consultor cego, que fez diagnóstico de pontos a serem ajustados, o que permitiu a continuidade do projeto em uma ação de extensão envolvendo uma discente que cursou a disciplina.

\section{Desenvolvimento dos projetos}

Para ilustrar os resultados obtidos, segue a apresentação com breve descrição de 03 projetos desenvolvidos na disciplina.

\section{Mapa tátil da sala expositiva}

O projeto nasceu da observação que o MCC, bem como suas exposições, não possui sinalização para cegos ou pessoas com baixa visão. Assim, a autonomia do cego fica restrita ao percurso estabelecido por mediador ou com acompanhante. A sinalização é necessária para a orientação espacial e para a circulação segura dos cegos. Considerando as restrições do MCC, a instalação do piso tátil nas exposições temporárias não é viável. Deste modo, os mapas táteis pareceram mais apropriados para o projeto. O grupo levantou referências sobre a construção de mapas táteis, com o intuito de coletar dados técnicos, legislação e materiais recomendados. Como solução o grupo sugeriu, para a entrada da sala expositiva, a produção de mapa tátil fixado em placa instalada na parede, respeitando a altura de 1 metro e inclinação de 15 graus. Respeitando a NBR 9050 (2015), foi estabelecido que o texto seria impresso em preto na fonte Arial, corpo 28 pts, caixa alta sobre fundo branco. Para a configuração do mapa, 
foram necessárias duas visitas técnicas ao museu para levantamento arquitetônico da sala expositiva. A planta da sala foi desenhada em software apropriado, o que facilitou a escolha de escala para a leitura de cegos adultos, a saber, 1:25. Sobre a planta impressa, o grupo iniciou estudos de cores privilegiando contrastes. Igualmente, foram estudados materiais e, considerando o custo e a fabricação manual, foi selecionado o E.V.A. para a confecção dos relevos. Inicialmente, o grupo acreditou que a utilização do E.V.A. de diferentes cores e espessuras seria o suficiente para a identificação do cego, entretanto, o consultor cego recomendou a utilização de textura nas superfícies das peças, para promover a diferenciação entre os elementos. Foi necessário também simplificar o uso de texturas nos elementos, para facilitar a identificação e leitura das legendas. Assim, as legendas foram agrupadas, como segue: painel expositivo, ave taxidermizada, balcão expositivo e representação tridimensional tátil.

Figura 1: Etapas de produção do mapa tátil. Autores do projeto Maria Gabrielle Figueirêdo e Victor Hugo Ferreira.
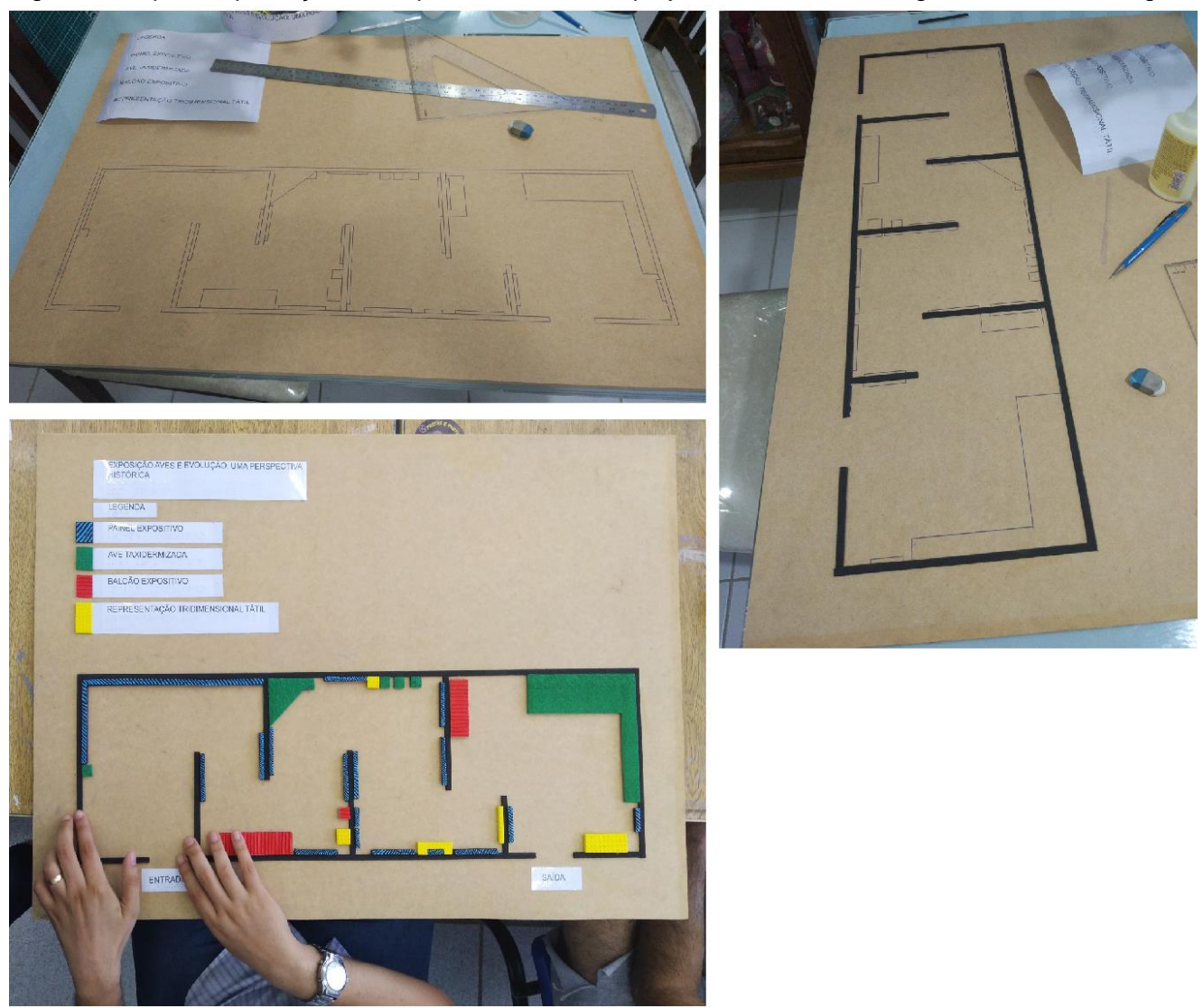

As fases de execução foram: [a] preparação da base rígida lixada (MDF 2mm de espessura, disponível na UFRN) no formato $80 \times 60 \mathrm{~cm}$, considerando a escala da planta e o espaço para legenda; [b] desenho e corte das paredes em E.V.A. preto, obedecendo a espessura indicada na escala 1:25; [c] construção das legendas em braille em máquina de escrever Perkins manual sobre folha de acetato; [d] impressão dos textos em fonte ampliada sobre papel sulfite, considerando a colagem sobre o acetato e a resistência da cola; [e] desenho da planta na base de madeira com auxílio de papel carbono; [f] confecção dos elementos que compõem a exposição, procurando estabelecer diferenças das textura; [g] colagem dos elementos na base com cola de madeira.

\section{Pranchas em revelo com representação das aves taxidermizadas}

Dentre os pontos discutidos nas etapas [4] e [5], os alunos apontaram a ausência de qualquer informação acessível para cegos e pessoas com baixa visão no ambiente das aves taxidermizadas, expostas no último ambiente da mostra. Assim, o grupo buscou conceber artefatos táteis, que representassem os animais expostos. Como resultado desenvolveram 
painéis com representação em relevo das principais espécies expostas, acompanhadas de recurso de audiodescrição. O primeiro passo foi observar as espécies de aves expostas e criar critério de seleção, visto que a leitura tátil é um processo cansativo e que demanda tempo para compreensão da informação. O grupo elegeu cinco espécies de diferentes tamanhos e características: Arara, Ema, Quero-quero, Suindara e Tucano. A pesquisa visual foi importante para levantar os contornos e as representações das aves selecionadas. Para o desenvolvimento deste projeto, adotou-se o método de Duarte (2011) para o ensino de desenho para crianças cegas, pois se assemelha ao processo de tradução tátil de obras observado em alguns museus, a exemplo da Pinacoteca do Estado de São Paulo. Para a autora o ensino do desenho segue as etapas: [a] reconhecimento do objeto em experiência tátil, para a compreensão do artefato; [b] planificação do desenho em superfície com espessura com emborrachados; [c] compreensão do contorno e assimilação das linhas do desenho com o dedo, obedecendo um sentido para fixação gráfica. Especificamente para o desenvolvimento de projeto foi considerada a etapa [b]. Duarte (2011) também recomenda o tamanho A3 para a contemplação, evitando a fragmentação da imagem. Assim, o grupo considerou este formato para o desenvolvimento das pranchas. Outro exemplo foi analisado: materiais didáticos produzidos pelo Istituto dei Ciechi di Milano, que levam em conta o conteúdo da prancha, utilizando a representação da ave em perfil e uma escala humana comparativa. Os modelos foram desenvolvidos em E.V.A. preto para prancha e amarelo para demais informações. O contraste favorece a identificação e a leitura das informações para pessoas com baixa visão. Os elementos foram cortados manualmente (Figura 2).

Figura 2: Etapas de produção das pranchas em revelo. Autores do projeto Gabriel Valentim, Ivana Sarcamento e Juciara Mesquita.
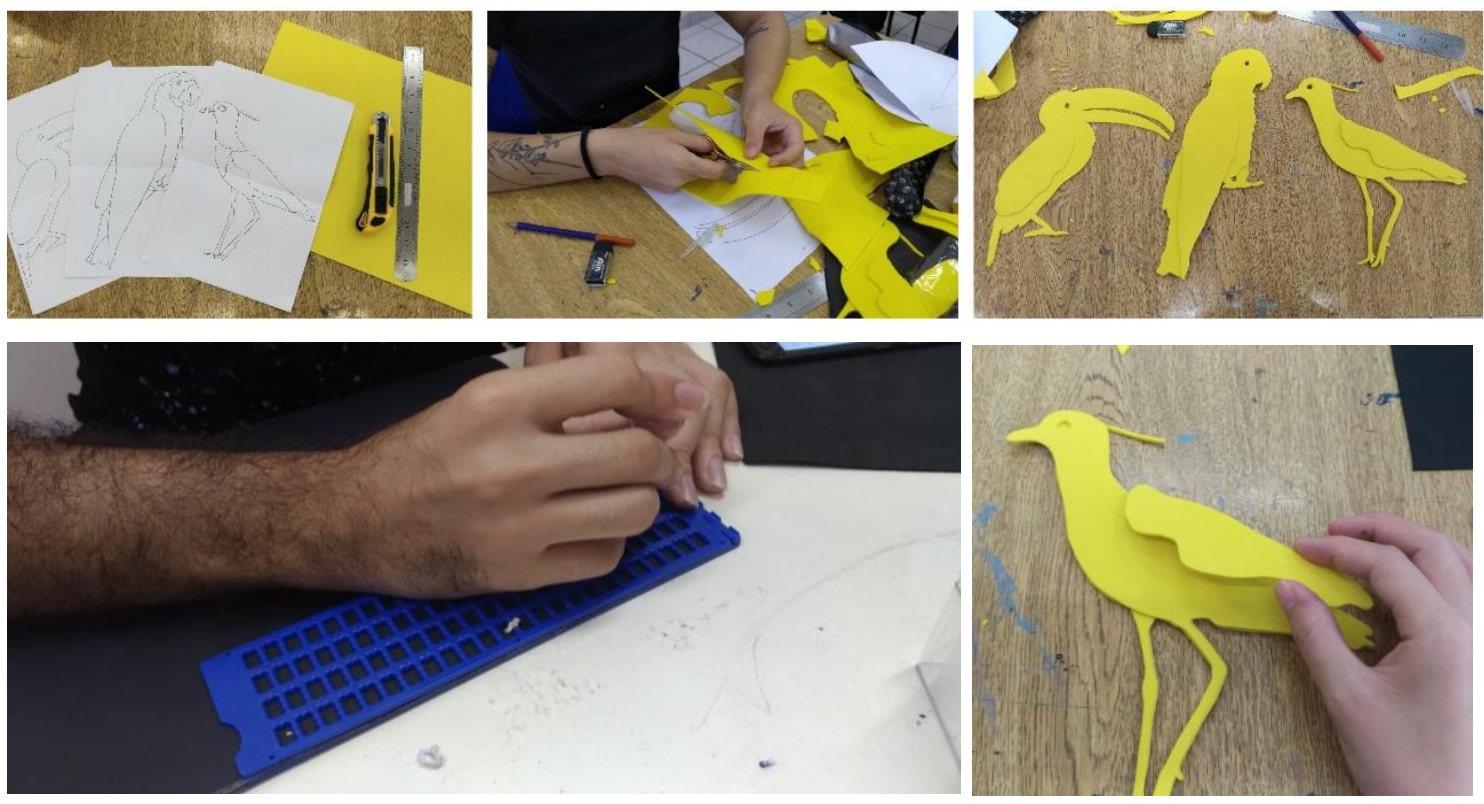

$\mathrm{Na}$ avaliação dos modelos preliminares os consultores observaram, que a construção de camadas de E.V.A. permitia diferenciar o volume e a profundidade, facilitando a percepção das pernas e das asas das aves. Também, fizeram considerações sobre a flexibilidade do E.V.A., assim, o modelo final foi produzido em papel paraná revestido de papel color plus preto, conferindo maior rigidez ao artefato. Esta escolha permitiu a produção do texto em braille com uma reglete positiva direto na prancha de color plus. Por fim, para facilitar a compreensão das informações, o consultor sugeriu alteração na disposição das informações, como segue: na parte superior à esquerda o nome da ave, seguindo da representação de escala e a ave centralizada na parte inferior. O modelo final foi produzido com as recomendações (Figura 3). 
Figura 3: Avaliação das pranchas táteis pelo consultor cego. Autores do projeto Gabriel Valentim, Ivana Sarcamento e Juciara Mesquita.
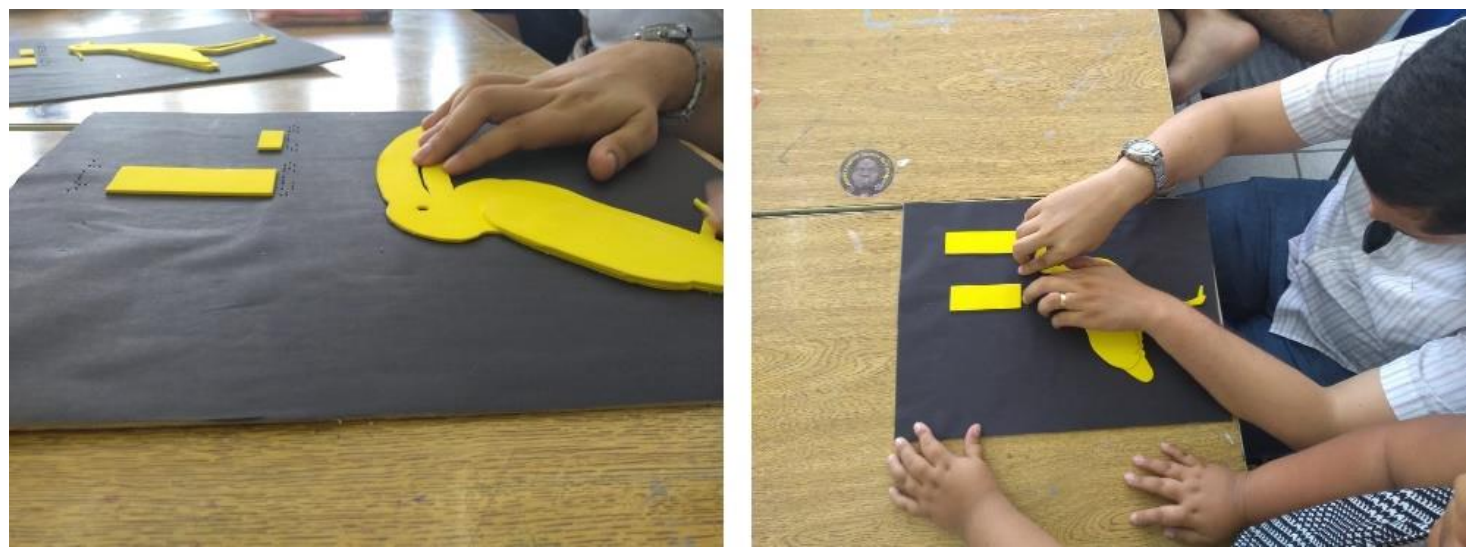

\section{Réplica tátil do fóssil Archaeopteryx lithographica}

O grupo identificou a falta de comunicação sensorial da réplica do fóssil, artefato fundamental para história da paleontologia e para a teoria da evolução. Trata-se de fóssil transicional entre dinossauros e pássaros modernos. O MCC possui em seu acervo uma réplica do original alemão, doado pelo Museu Histórico Nacional. Objeto de destaque na exposição, a réplica está em uma caixa de vidro com iluminação na lateral e fixada na parede: informação visual, que não pode ser contemplada por cegos e pessoas com baixa visão, até porque sua identificação ou o conteúdo informativo sobre o fóssil, não foi reproduzido em multiformato (impresso em fonte ampliada, em braille ou áudio).

As fases de problematização e geração de ideias foram desenvolvidas a partir de brainstorming, que levou à solução - reprodução tátil simplificada da réplica e um painel com texto em braille e fonte ampliada. A partir daí os alunos desenvolveram uma série de desenhos para a representação do fóssil. Na fase seguinte, avaliaram materiais para a reprodução tátil, como o biscuit e a cerâmica fria, levando em conta a flexibilidade para modelagem. O primeiro modelo em baixo relevo foi desenvolvido em biscuit, em escala reduzida (Figura 4).

Figura 4: Decalque para produção de modelo preliminar em baixo relevo. Autores do projeto Amannda Gomes e Rafael Ferreira.
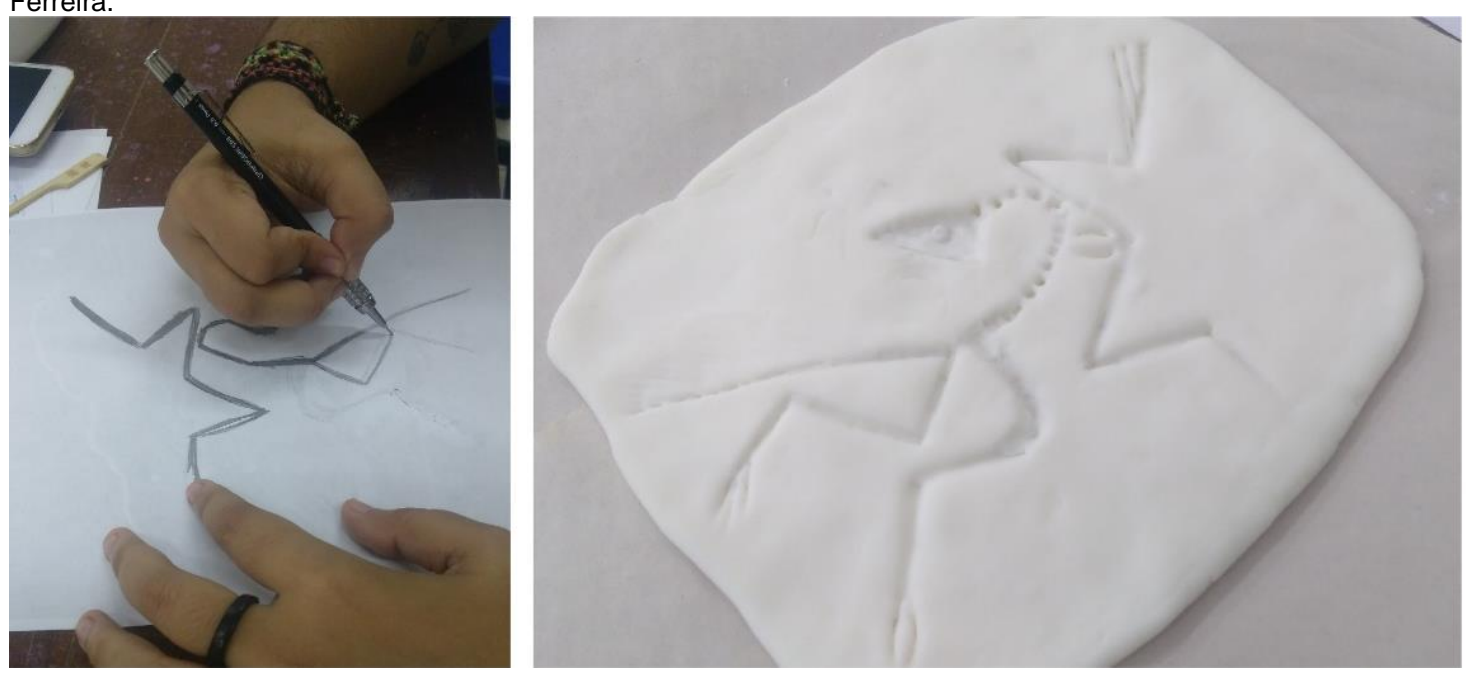

Entretanto, a partir da participação do consultor cego, este modelo foi descartado por não permitir uma leitura clara do desenho. Também, o grupo considerou manter a escala real da 
peça. A solução compreendeu uma prancha em relevo em duas cores contrastantes, relevo em preto sobre base branca, focando o visitante com baixa visão. A partir de esboços os discentes partiram para a representação das partes fósseis em alto relevo e, em baixo relevo os resquícios de penas e demais marcas da argila na base do artefato. Uma reprodução fotográfica impressa do fóssil em escala serviu de guia para modelagem do esqueleto. A imagem também foi utilizada para transferir as linhas principais do fóssil, aplicando a técnica do decalque, o que facilitou a modelagem da base (Figura 5).

Figura 5: Etapas de produção da réplica tátil do fóssil Archaeopteryx lithographica. Autores do projeto Amannda Gomes e Rafael Ferreira.

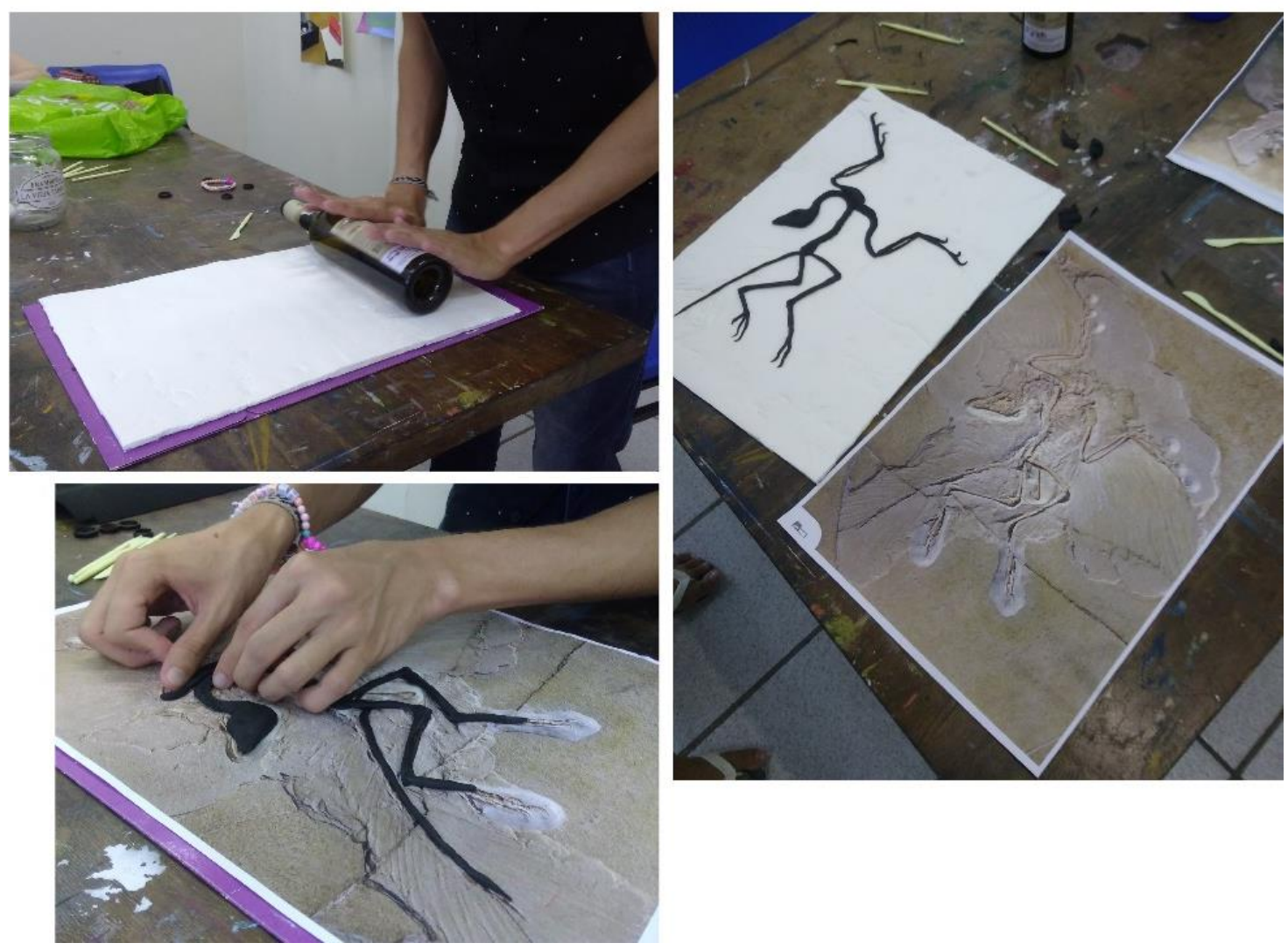

O primeiro passo para a transcrição do texto foi verificar a dimensão que o braille ocuparia na prancha. Assim, identificou-se que o formato adotado pela prancha poderia ser semelhante ao da representação tátil do fóssil. A partir do conteúdo adquiro em aula, o grupo optou por trabalhar com camadas, texto impresso em preto no fundo branco e, acima, a impressão em braille. O texto em fonte ampliada (corpo 28pts) foi impresso em impressora laser sobre papel no formato A3. O texto em braille foi impresso no Laboratório de Acessibilidade da UFRN, utilizando uma folha de acetato de $20 \mathrm{~mm}$ e a impressora braille.

O modelo final foi avaliado pelo consultor cego que, apesar da dificuldade de ler a imagem em relevo pela complexidade da informação, considerou a peça agradável ao toque e com desenhos bem definidos. Observou-se que, mesmo com a legenda explicativa, a reprodução tátil do fóssil não apresenta autonomia comunicacional, o que requer a explicação de mediador. Vale destacar que a reprodução tátil, além de atender ao público específico, pode ser tocada por todos os visitantes, o que aumenta a experiência sensorial na exposição. Ademais, o material escolhido apresentou deformações: no processo de secagem a placa envergou (Figura 6). Assim, foram feitos ajustes posteriores para implantação no MCC. 
Romani, E., Bastos, H. R., \& Liberalino, I. R. M. | Comunicação sensorial no Museu Câmara Cascudo da Universidade Federal do Rio Grande do Norte: uma experiência didática

Figura 6: Avaliação do modelo em baixo relevo e da réplica tátil em alto relevo pelo consultor cego. Autores do Projeto Amannda Gomes e Rafael Ferreira.
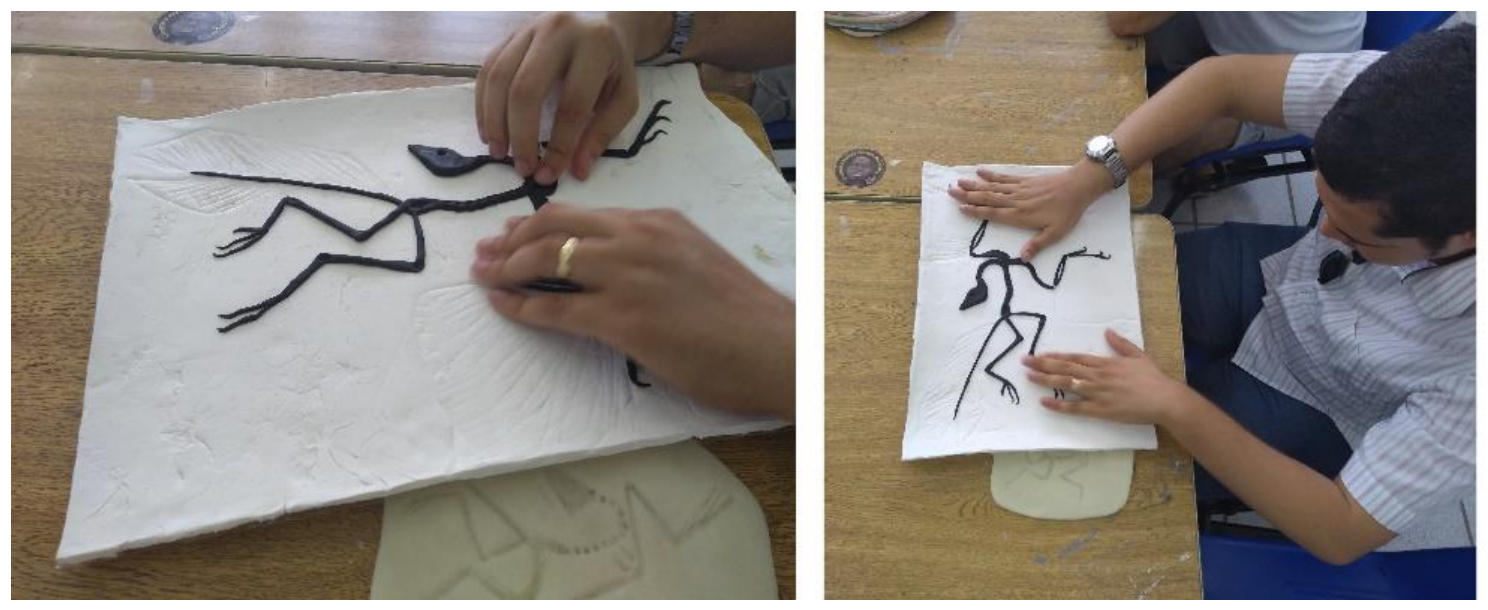

\section{Desdobramentos}

Após o encerramento da disciplina, as peças foram levadas para o MCC para serem avaliadas e utilizadas pelo setor educativo. O processo de aperfeiçoamento dos artefatos contou com a participação de uma aluna da disciplina, atualmente bolsista no Museu, executando algumas modificações para aumentar a durabilidade das peças e outras para a implantação na sala expositiva. Seguem as modificações executadas:

1. Mapa tátil: o artefato foi desenvolvido embasado na previsão dos locais de uso das demais peças de acessibilidade desenvolvidas pelos grupos. Após a finalização de todos os artefatos e a implantação na sala expositiva, foi necessário alterar a localização de uma das peças táteis.

2. Réplica do fóssil Archaeopteryx lithographica: foi fixada em placa de madeira pintada de preto junto com sua legenda de identificação, para viabilizar sua fixação no ambiente.

3. Pranchas em revelo com representação das aves: para aumentar a durabilidade do material, as placas de papel cartão das bases foram substituídas por placas de PVC pintadas em preto e as legendas em braille foram produzidas em acetato e fixadas nas placas.

As novas peças foram reavaliadas em visitas agendadas, nos dias 03/04 e 08/05/2019, com público diverso. Na primeira visita participou público mais abrangente - visitantes de 18 a 60 anos não cegos, 1 cego e 2 visitantes com mobilidade reduzida. Na segunda visita foram convidados 2 cegos e 1 pessoa com baixa visão. Nas duas oportunidades os visitantes percorreram toda a exposição, para avaliar também o papel da mediadora no processo de transmissão do conhecimento. Foram levantados alguns pontos importantes quanto o acesso às informações: a necessidade de audiodescrição para os cegos que não conhecem o código braille e a durabilidade dos artefatos acessíveis. 
Romani, E., Bastos, H. R., \& Liberalino, I. R. M. | Comunicação sensorial no Museu Câmara Cascudo da Universidade Federal do Rio Grande do Norte: uma experiência didática

Figura 7: Pranchas em revelo com representação das aves aperfeiçoadas e avaliação do mapa tátil e da réplica do fóssil pelos visitantes cegos durante visita mediada no MCC. Autora das modificações Isadora Rocha.
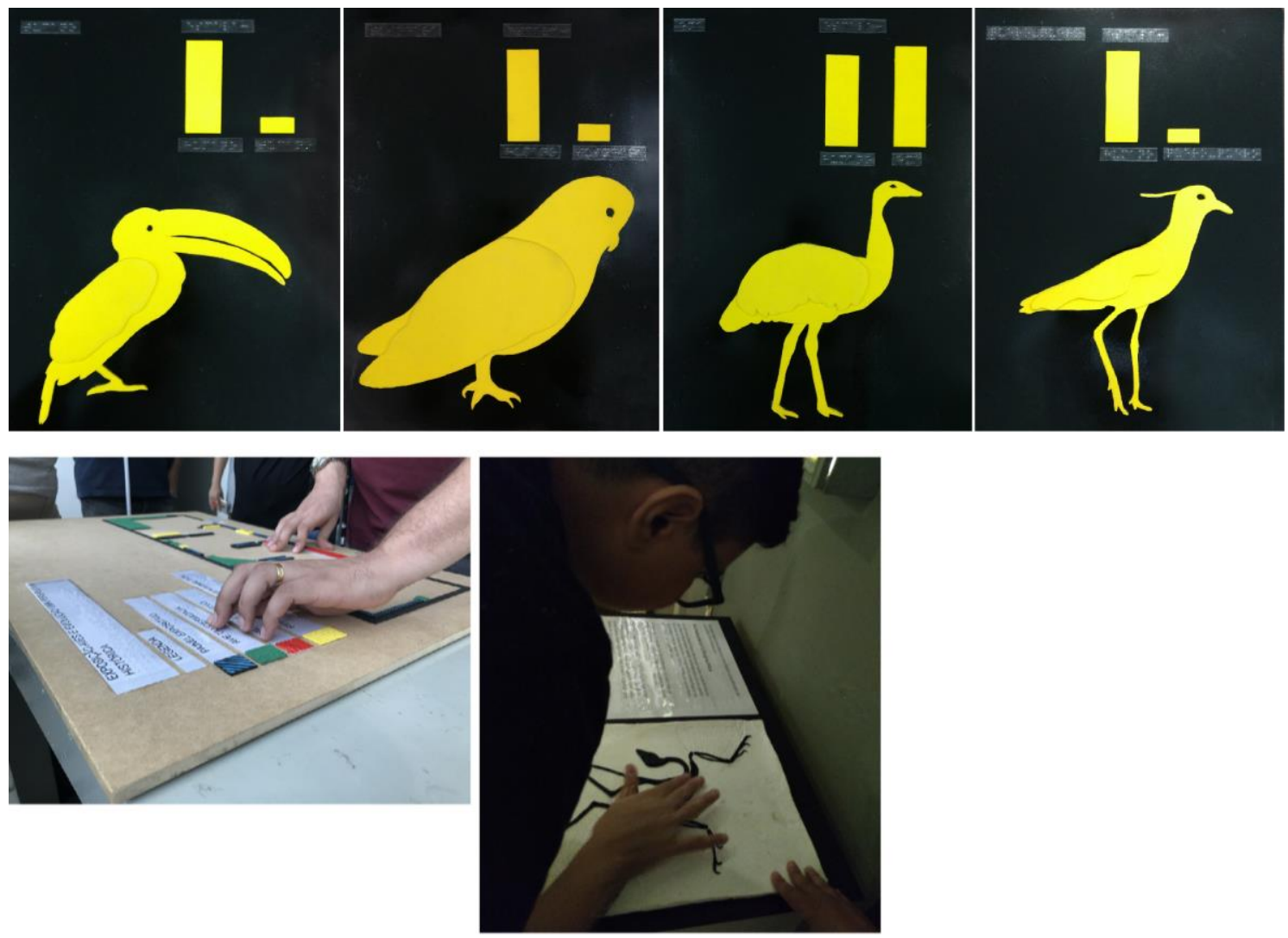

\section{Considerações finais}

O processo de ensino-aprendizagem adotado atingiu os objetivos propostos na disciplina, sensibilizando os discentes para questões relacionadas à acessibilidade. Porém, por se tratar de um processo, pode-se considerar que a experiência foi o início de futuros projetos de extensão e de pesquisa, que devem contribuir para a investigação e o desenvolvimento de recursos sensoriais em 2019-2 e 2020.

A participação dos consultores com deficiência visual no processo de desenvolvimento de artefato sensorial foi fundamental para discutir possíveis melhorias nas peças produzidas. Ademais, os consultores trouxeram suas experiências pessoais durante as aulas expositivas, conhecimento e percepções singulares. Cabe ainda destacar, que as visitas agendadas no museu levantaram outras possibilidades de projeto de artefatos sensoriais, uma vez que cada visitante ou consultor com deficiência apresenta diferentes repertórios e experiências.

\section{Referências}

Amiralian, M.L.T.M. (1997). Compreendendo o cego: uma visão psicanalítica da cegueira por meio de desenhos-estórias. São Paulo: Casa do Psicólogo.

Araújo, M.M., \& Bruno, M.C.O. (Org.) (1995) A memória do pensamento museológico contemporâneo: documentos e depoimentos. São Paulo: Comitê Brasileiro do ICOM.

Associação Brasileira de Normas Técnicas - ABNT. (2015) NBR 9050: Acessibilidade a edificações, mobiliário, espaços e equipamentos urbanos. Rio de Janeiro: ABNT, 2015.

Brasil. Presidência da República. (2015). Lei Brasileira de Inclusão da Pessoa com Deficiência. Lei no 13.146, de 6 de julho de 2015. 
Romani, E., Bastos, H. R., \& Liberalino, I. R. M. | Comunicação sensorial no Museu Câmara Cascudo da Universidade Federal do Rio Grande do Norte: uma experiência didática

Cambiaghi, S. (2007) Desenho Universal: métodos e técnicas para arquitetos e urbanistas. São Paulo: Editora Senac São Paulo.

Cardoso, E., \& Cuty, J. (Org.) (2012). Acessibilidade em ambientes culturais. Porto Alegre: Marca Visual.

Duarte, M.L.B., \& Piekas, M.I. (Org.). (2011). Desenho infantil em pesquisa: imagens visuais e táteis. Curitiba: Editora Insignt,.

Lupton, E. (org.).(2013). Intuição, ação, criação: graphic design thinking. São Paulo: GGili.

Preiser, W.F.E., \& Ostroff, E. (Org.).(2001). Universal Design Handbook. New York: MacgrawHill.

Sanders, E.B. (2002). From User-Centered to Participtory Design Approches. In: Frascara, J. (ed.). Design and the Social Sciences: making connections. London: Taylor \& Francis.

Sanders, E. B., \& Stappers, P.J. (2008). Co-creation and the new landscapes of design. CoDesign International Journal of CoCreation in Design and the Arts, 4(1), pp. 5-18.

Sarraf, V.P. (2015). Acessibilidade em espaços culturais: mediação e comunicação sensorial. São Paulo: Educ; Fapesp.

Sassaki, R. (1997). Inclusão: onstruindo uma sociedade para todos. Rio de Janeiro: WVA.

Spinuzzi, C. (2005). The Methodology of Participatory Design. Technical Communication, 52 , (2), pp. $163-174$.

Tojal, A.F. (2010). Acessibilidade e inclusão de públicos especiais em museus. In: Caderno de acessibilidade: Reflexões e Experiências em Museus e Exposições. São Paulo: Expomus.

Ulbricht, V.R.; Fadel, L., \& Batista, C.R. (Org.) (2017). Design para acessibilidade e inclusão [livro eletrônico]. São Paulo: Blucher.

\section{Sobre as autoras}

Elizabeth Romani, PhD, UFRN, Brasil <romanibeth@gmail.com> Helena Rugai Bastos, PhD, UFRN, Brasil <helenarugai@gmail.com> Isadora Rocha de Medeiros Liberalino, UFRN, Brasil <isadoraliberalino@gmail.com> 